\title{
USO DE INSETICIDAS ORGANOFOSFORADOS NOS PÓLOS DE PRODUÇÃO NA ILHA DE SÃO LUÍS(MA): CONDIÇÕES DE TRABALHO E CONTAMINAÇÃO DE HORTALIÇAS
}

\author{
SORAYA MARIA MENDONÇA ARAÚJO * \\ RAIMUNDA NONATA SANTOS DE LEMOS ** \\ MARIA ELIANA RIBEIRO DE QUEIROZ *** \\ GILVANDA SILVA NUNES
}

\begin{abstract}
Avaliou-se a forma de utilização de pesticidas nos pólos de produção da Ilha de São Luís (MA), Brasil. Foram analisadas algumas hortaliças cultivadas tendo sido detectados resíduos do inseticida organofosforado Metamidofós em amostras de tomate, pimentão e coentro. Embora os níveis de contaminação tenham sido relativamente baixos, a presença do pesticida atesta a falta de informação do pequeno produtor rural que aplica agrotóxicos de forma indiscriminada, sem obedecer os períodos de carência para cada cultura.
\end{abstract}

PALAVRAS-CHAVE: HORTALIÇAS; INSETICIDA ORGANOFOSFORADO.

\section{INTRODUÇÃO}

As pragas, doenças e ervas invasoras constituem-se em fatores limitantes da produção de alimentos nos agroecossistemas que apresentam desequilíbrio ambiental. Na tentativa de resolver estes problemas, os agrotóxicos têm sido aplicados de forma indiscriminada devido as próprias características culturais do trabalhador rural, como a falta de capacitação profissional e de assistência técnica e propaganda enganosa.

* Engenheira Agrônoma, Mestre em Agroecologia, Universidade Estadual do Maranhão (UEMA), São Luís, MA.

** Professora, Departamento de Fitotecnia, UEMA, São Luís, MA.

*** Professora, Departamento de Química, Universidade Federal de Viçosa (UFV), Viçosa, MG.

Professora, Departamento de Tecnologia Química, Universidade Federal do Maranhão (UFMA), São Luís, MA. (e-mail: vandasn@terra.com.br). 
A generalização do uso de agrotóxicos, após a ll Guerra Mundial, gerou aumento na produção de alimentos e, conseqüentemente, problemas de intoxicação, contaminação do solo, da água e do ar, além da bioacumulação e efeitos adversos ao ecossistema que dificilmente são detectados a curto prazo (1).

Os impactos ambientais da utilização dos agrotóxicos na agricultura passaram a ser discutidos não só pelos movimentos ambientalistas, mas também pela população interessada em uma alimentação mais saudável. Na produção de hortaliças, importantes fornecedoras de vitaminas e de sais minerais, têm sido empregadas quantidades indiscriminadas de pesticidas, acarretando problemas de intoxicação de produtores rurais, presença de resíduos nos vegetais e contaminação da água e do solo. Isto se deve ao fato destas culturas serem vulneráveis à ação de pragas e doenças e apresentarem ciclo curto.

O Brasil representa o quinto mercado consumidor mundial de pesticidas constituindo-se no maior produtor e consumidor de agrotóxicos do terceiro mundo (2). Somente para exemplificar, no primeiro trimestre de 1999 a comercialização de agrotóxicos no país alcançou US\$242,5 milhões. No campo das importações, o Brasil gastou, somente em 1998, US $\$ 1,3$ bilhão. A dependência de $50 \%$ do mercado externo, segundo a ANDEF (2), é decorrente do rápido desenvolvimento de novas composições moleculares produzidas em poucas fábricas no mundo.

Dos produtos fitossanitários, os herbicidas são os mais utilizados em todo o mundo, tanto em volume, como em área tratada. O uso destes produtos em cereais, soja, beterraba e cana-de-açúcar equivale a $78 \%$ do total comercializado no mundo. O restante corresponde a inseticidas, fungicidas, nematicidas, acaricidas, moluscicidas, rodenticidas e outros (3). Os herbicidas também são os mais utilizados nas lavouras brasileiras, principalmente, nas culturas de soja, de cana-de-açúcar e de milho (2), sendo seguidos pelos inseticidas e fungicidas.

Segundo a ASSOCIAÇÃO AGROECOLÓGICA TIJUPÁ (4) até meados de 1993 a difusão de agrotóxicos, no Estado do Maranhão, era feita principalmente pelos órgãos do Sistema de Agricultura, além de cooperativas agrícolas, comércios de produtos agropecuários, meios de comunicação e até aconselhamento entre os próprios agricultores. Com a extinção dos principais organismos agrícolas do Maranhão, a situação se agravou pela falta de informação básica destinada ao agricultor, sobretudo ao pequeno produtor rural.

Os produtos mais utilizados no Maranhão, alguns destes proibidos no Brasil, são: Endrex, Folidol, Aldrin, Folisuper, Enterex, Malagran, Formicidol, Forfine, Dithane M45, Cupravit Azul, Mansat, Benlate, Ambush, Malatol, Shelgran, Diazinon, Dipterex, Mirex granulado, Paration, Thordon 2,4-D, Gramoxone, Arrozan, Propanin, Furadan, Abridion, Ratac, Mil gato, 
Blasticidina S, DMA 720, Tamaron, Hinosan, Heptacloro, Carbaril, Captan, $\mathrm{DDH}, \mathrm{BHC}$ e Machete (4-6).

De acordo com dados da CODEA (6), o consumo de agrotóxicos no Maranhão, até o ano de 1998, correspondeu a cerca de 1,11 toneladas e 592 mil litros de herbicidas, principalmente nos municípios de Balsas, Imperatriz, Santa Inês, Açailândia, Bacabal e Presidente Dutra; 34,5 toneladas e 165 mil litros de inseticidas nos municípios de Balsas, Imperatriz, Presidente Dutra, Açailândia, Bacabal, Colinas e Gonçalves Dias; 34,3 toneladas e 22,3 mil litros de fungicidas em Balsas, Imperatriz, Presidente Dutra e Dom Pedro; e 40,5 mil litros de espalhante adesivo em Balsas, Açailândia e Imperatriz.

A preocupação com os efeitos que os pesticidas causam aos ecossistemas e agroecossistemas e aos seres humanos é urgente e prioritária na definição de políticas públicas que levem em consideração não só a questão econômica, mas, principalmente, as questões ambiental e social, incluindo, neste contexto, a saúde da população.

Com a realização deste trabalho pretendeu-se avaliar a forma de utilização dos agroquímicos nas lavouras de pólos agrícolas, localizados na llha de São Luís (MA) e adjacências, além de verificar as maneiras de descarte das embalagens dos agrotóxicos usados pelos agricultores. Também foram estudados os níveis de contaminação por inseticidas organofosforados à base de Metamidofós e Paration metílico, largamente aplicados nas hortaliças produzidas nestes pólos e comercializadas na capital maranhense.

\section{MATERIAL E MÉTODOS}

\subsection{ESTRUTURAÇÃO DO ROTEIRO DE ENTREVISTA}

O roteiro de entrevista foi dividido em duas partes estruturadas da seguinte forma: a primeira parte referiu-se ao perfil tecnológico do produtor abordando o sistema de produção utilizado, o tipo de assistência técnica recebida, a utilização de receituário agronômico para aquisição de agrotóxicos e o mercado consumidor. A segunda parte envolveu informações pertinentes ao processo de aplicação de pesticidas:

- produtos aplicados para o controle de pragas (inseticidas mais utilizados pelos produtores);

- dosagens aplicadas (quantidade do produto aplicado em cada pulverização);

- utilização de equipamentos de segurança e de proteção individual 
(EPI) durante o processo de preparo da calda e pulverização do produto;

- período de carência (intervalo em dias que decorrem da última aplicação do agrotóxico à colheita);

- destino das embalagens (local utilizado pelos produtores para descartar as embalagens vazias).

\subsection{APLICAÇÃO DO ROTEIRO DE ENTREVISTA NOS PÓLOS DE PRODUÇÃO}

O roteiro de entrevista preparado foi aplicado nos pólos de produção, municípios de São Luís, Paço do Lumiar, Raposa e São José de Ribamar. Dos vinte e dois pólos de produção, apontados pelo Instituto Municipal de Produção e Renda (São Luís, MA), foram pesquisados os mais representativos (quatorze) em termos de produção de hortaliças e comercialização nas feiras livres de pequenos produtores rurais (Tabela 1). Os produtores entrevistados, também indicados pelo Instituto, representaram as lideranças de cada pólo.

\subsection{COLETA DE HORTALIÇAS PRODUZIDAS NOS PÓLOS DE PRODUÇÃO}

Foram escolhidos, aleatoriamente, seis pólos de produção, dos quatorze mais representativos, e da mesma forma efetuada a amostragem de 4 hortaliças (Tabela 2). As coletas foram realizadas em feiras livres, com $500 \mathrm{~g}$ de tomate (Lycopersicum esculentum Mill.) e de pimentão (Capsicum annum, L.), quatro maços de couve (Brassica oleracea L.) e de coentro (Coriandrum sativum L.), com quatro repetições cada, totalizando dezesseis amostras por coleta. As amostras foram devidamente embaladas em sacos plásticos transparentes, com fecho hermético, identificadas e acondicionadas em freezer para fins de conservação.

\subsection{DETERMINAÇÃO DOS RESÍDUOS DE PESTICIDAS NAS AMOSTRAS VEGETAIS}

Foram analisados resíduos dos inseticidas organofosforados Metamidofós e Paration metílico, mais freqüentemente empregados nos pólos de produção para proteção das culturas das hortaliças investigadas. 
TABELA 1 - NÚMERO DE PRODUTORES ENTREVISTADOS NOS PÓLOS DE PRODUÇÃO NA ILHA DE SÃO LUÍS (MA)

\begin{tabular}{|c|c|c|}
\hline Munic pios & P los de produ a & $\begin{array}{c}\text { Nœmero de } \\
\text { produtores } \\
\text { entrevistados } \\
\end{array}$ \\
\hline $\mathrm{S}^{\mathrm{a}} \circ \mathrm{LuS}$ & $\begin{array}{c}\text { Coquilho } \\
\text { Taja uaba } \\
\text { S }^{\text {a o C ristov }} \text { o II } \\
\text { Itapera } \\
\text { Anajatiua } \\
\text { Quebra-pote } \\
\text { Pedrinhas } \\
\text { Igaraœ }\end{array}$ & $\begin{array}{l}1 \\
1 \\
1 \\
1 \\
1 \\
2 \\
2 \\
1\end{array}$ \\
\hline Pa o do Lumiar & $\begin{array}{c}\text { Igua ba } \\
\text { Merc Cs } \\
\mathrm{S}^{\mathrm{a}} \circ \mathrm{J}^{\mathrm{a}} \text { o da Boa } \\
\text { Vista }\end{array}$ & $\begin{array}{l}1 \\
3 \\
2\end{array}$ \\
\hline Raposa & Cumbique & 2 \\
\hline $\mathrm{S}^{\mathrm{a}} \mathrm{O}$ Jos $\varnothing$ de Ribamar & $\begin{array}{c}\text { Santa Maria } \\
\text { Andiroba }\end{array}$ & $\begin{array}{l}1 \\
1\end{array}$ \\
\hline Total & 14 & 20 \\
\hline
\end{tabular}

\section{TABELA 2 - HORTALIÇAS COLETADAS DOS PRODUTORES RURAIS NAS FEIRAS LIVRES, EM SÃO LUÍS (MA)}

Sํㅡ Jo ${ }^{\underline{a}}$ o da Boa Vista e Igua ba

Couve

$\mathrm{S}^{\mathrm{a}}$ o Jo $\mathrm{J}^{\mathrm{a}}$ o da Boa Vista, Cumbique e

Coentro

Igua ba

Andiroba

Tomate

Itapera, Igua ba e Coquilho

Piment ${ }^{a}$ o 


\subsubsection{Limpeza do Material}

Para evitar qualquer tipo de contaminação, a vidraria empregada nesta etapa do trabalho foi lavada, seqüencialmente, com solução de extran alcalino (Merck) a 20\%, água potável abundante, água deionizada e, por fim, acetona grau resíduo. Após este procedimento, a vidraria foi seca ao ar, antes do uso.

\subsubsection{Soluções e Reagentes}

Todos os solventes utilizados foram de grau resíduo, redestilados (Merck) e de elevada pureza (>96\%). As soluções dos padrões de pesticidas (Metamidofós e Paration metílico) foram preparadas da seguinte forma:

- solução estoque - preparada por dissolução de adequada quantidade do padrão (Dr. Ernstentorfer, Alemanha, pureza > 99\%) em certo volume de metanol, de modo a perfazer concentração final de $1000 \mathrm{mg} \cdot \mathrm{L}^{-1}$;

- soluções de trabalho - preparadas por diluição da solução estoque, em volumes variados do solvente, de modo a perfazer diferentes concentrações (10, 5, 2 mg. $\mathrm{L}^{-1}$, etc);

- curvas padrão - preparadas por diluições sucessivas de uma solução de trabalho, de modo a construir os pontos de calibração. As concentrações das curvas para o Metamidofós foram: 353-176-88 $-44-22$ e $0 \mu \mathrm{g} \cdot \mathrm{L}^{-1}$ e para o Paration metílico de: $10-5-2,5-1,25$ $-0,625-0,3125-0,15625$ e $0 \mathrm{mg} \cdot \mathrm{L}^{-1}$.

\subsubsection{Preparação dos Extratos Cromatográficos}

As metodologias empregadas para obtenção dos extratos foram baseadas nos procedimentos descritos pelo FOOD AND DRUG ADMINISTRATION (7), com algumas modificações.

\section{- Análise do Metamidofós}

Em $20 \mathrm{~g}$ de amostra, previamente triturada em liquidificador (com copo de aço inoxidável), foram adicionados $20 \mathrm{~mL}$ de metanol, seguido de agitação mecânica por 20 min para a extração do pesticida. Procedeu-se filtração 
a vácuo, utilizando funil de Büchner e papel filtro qualitativo de modo a separar o extrato do bagaço. Durante a filtração foram efetuadas duas lavagens com $5 \mathrm{~mL}$ de acetonitrila. O bagaço foi descartado e o filtrado eluído em coluna de vidro ( $20 \mathrm{~cm}$ de comprimento e $2 \mathrm{~cm}$ de diâmetro), contendo $5 \mathrm{~g}$ de sulfato de sódio anidro, visando retirar a água presente. Seguiu-se a etapa de purificação do extrato (clean up) passando-se o extrato metanólico através de cartucho de extração em fase sólida (Solid Phase Extraction - SPE, Merck), com 500 mg de capacidade, contendo como fase estacionária sílica ligada ao grupamento amínico $\left(\mathrm{NH}_{2}\right)$. Nesta etapa foi utilizada mistura binária acetonitrila/metanol (3:1) como eluente, em 3 porções de $5 \mathrm{~mL}$. As porções foram combinadas e recolhidas em balão de fundo redondo, com capacidade para $100 \mathrm{~mL}$ (Pyrex), após eluição. Os procedimentos para uso dos cartuchos SPE, destinados à purificação de extratos contendo pesticidas, foram detalhadamente descritos por NUNES et al. (8). O eluato final (a combinação das 3 porções do eluente, contendo o resíduo do pesticida, e mais alguns co-extrativos) foi evaporado em evaporador rotatório (Jank KI - Tkunkel, Alemanha), a $35^{\circ} \mathrm{C}$ até secura. $\mathrm{O}$ resíduo final foi redissolvido em $2 \mathrm{~mL}$ de acetato de etila, cujo volume foi medido com precisão por meio de pipeta automática (Gilson Medical, França). Finalmente, filtrou-se o extrato em filtro Millex (Millipore) de $0,45 \mu$ m de diâmetro de poro, antes da análise cromatográfica.

\section{- $\quad$ Análise do Paration metílico}

Em $20 \mathrm{~g}$ da amostra, previamente triturada em liquidificador, foram adicionados $100 \mathrm{~mL}$ de acetona, seguido de agitação mecânica por 15 minutos para a extração do pesticida. Procedeu-se a filtração a vácuo, tendo sido efetuadas quatro lavagens com $5 \mathrm{~mL}$ de acetonitrila. $O$ bagaço foi relavado com duas porções de acetonitrila, antes de ser descartado, e o filtrado (combinação de todas as lavagens) submetido à etapa de partição líquido-líquido (PLL), visando separar parte dos co-extrativos da amostra (pigmentos, água, açúcares, lipídios, entre outros). O extrato acetônico foi transferido para funil de decantação, com $250 \mathrm{~mL}$ de capacidade (Pyrex), sendo adicionados $100 \mathrm{~mL}$ da mistura éter de petróleo/diclorometano (1:1). Após agitação por cerca de meia hora e repouso por $10 \mathrm{~min}$, as fases foram separadas. A porção aquosa foi transferida para segundo funil de decantação e reparticionada com $50 \mathrm{~mL}$ da mistura éter de petróleo/ diclorometano (1:1). A fase orgânica combinada foi conduzida à etapa de purificação do extrato (clean up), para a qual empregou-se cartucho de extração em fase sólida (Solid Phase Extraction - SPE, Merck), com $500 \mathrm{mg}$ de capacidade, contendo como fase estacionária sílica ligada ao 
grupamento octadecil ( $\left.\mathrm{C}_{18}\right)$. Para a eluição do pesticida utilizou-se volume de $20 \mathrm{~mL}$ da mistura metanol/diclorometano (1:1), distribuído em 4 porções de $5 \mathrm{~mL}$. O eluato final foi evaporado em evaporador rotatório, a $35^{\circ} \mathrm{C}$, até secura. O resíduo foi redissolvido em $2 \mathrm{~mL}$ de acetato de etila e o extrato final filtrado em filtro Millex (Millipore) antes da análise cromatográfica.

\subsubsection{Ensaios de Recuperação}

Para determinar a eficiência das metodologias analíticas empregadas, amostras de vegetais foram fortificadas em dois níveis de concentração do pesticida Metamidofós: $3 \mathrm{mg} \mathrm{Kg}^{-1}$ (tomate) e 0,05 mg. Kg ${ }^{-1}$ (pimentão). Para exemplificar, no nível de fortificação $3 \mathrm{mg} \cdot \mathrm{Kg}^{-1}$, o seguinte procedimento foi adotado: em $20 \mathrm{~g}$ da amostra de tomate foram adicionados $600 \mu \mathrm{L}$ da solução de trabalho de $100 \mathrm{mg}^{\mathrm{L}} \mathrm{L}^{-1}$ em Metamidofós, perfazendo concentração final, na amostra, de $3 \mathrm{mg} . \mathrm{Kg}^{-1}$ (3 ppm). Seguiu-se, então, o procedimento de preparo dos extratos recomendado no item 2.4.3, após período de repouso de 20 minutos para acondicionamento da matriz vegetal com o pesticida. Para o Paration metílico foram realizados dois ensaios de recuperação no mesmo tipo de amostra (couve), com a concentração de $0,04 \mathrm{mg} / \mathrm{Kg}$ (40 ppb).

\subsubsection{Determinações Cromatográficas}

Para as análises dos extratos vegetais empregou-se sistema cromatográfico a gás SHIMADZU, modelo GC 17A, acoplado a dois diferentes detectores, ou seja, detector termiônico em chama (FTD) e detector seletivo para nitrogênio-fósforo (NPD). As condições cromatográficas foram as seguintes:

\section{a) Análise do Metamidofós}

- temperatura injetor: $250^{\circ} \mathrm{C}$;

- coluna capilar: BP-5 $30 \mathrm{~m}$ x 0,25 (d.i.) e $1 \mu \mathrm{m}$ de espessura de filme;

- fase estacionária: 95\% metilpolissiloxano e 5\% fenilsiloxano;

- programação de temperatura: $130^{\circ} \mathrm{C} \stackrel{10^{\circ} \mathrm{C} / \mathrm{min}}{\longrightarrow} 200^{\circ} \mathrm{C}$;

- temperatura detector (FTD): $290^{\circ} \mathrm{C}$;

- volume injetado: $1 \mu \mathrm{L}$;

- gás de arraste: № ultrapuro; 
- fluxo do gás: 1,2 mL.min-1;

- razão split: 1:1.

b) Análise do Paration metílico:

- temperatura injetor: $230^{\circ} \mathrm{C}$;

- coluna capilar: BP-5 $30 \mathrm{~m}$ x 0,25 (d.i.) e $1 \mu \mathrm{m}$ de espessura de filme;

- fase estacionária: $95 \%$ metilpolissiloxano e 5\% fenilsiloxano;

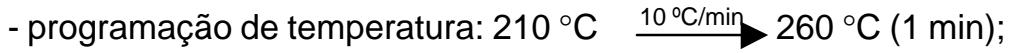

- temperatura detector (NPD): $250^{\circ} \mathrm{C}$;

- volume injetado: $1 \mu \mathrm{L}$;

- gás de arraste: N2 ultrapuro;

- fluxo do gás: 1,0 mL. $\mathrm{min}^{-1}$;

- razão split: 1:1.

Soluções de padrões com concentrações conhecidas foram injetadas mediante seringa de $1 \mu \mathrm{L}$ de capacidade (Hamilton), no sistema cromatográfico para a construção das curvas de calibração. O mesmo volume de injeção foi utilizado nas análises dos extratos. O pico relativo ao pesticida estudado foi rastreado, segundo o seu tempo de retenção, integrado automaticamente e a área anotada para realização dos cálculos de concentração. Os cálculos foram baseados na curva de calibração, construída diariamente. Para cada amostra foram realizadas duas injeções e tomados os valores das médias das áreas dos picos.

\section{RESULTADOS E DISCUSSÃO}

\subsection{PERFIL TECNOLÓGICO DOS PRODUTORES}

Nos quatorze pólos pesquisados (Tabela 1) os produtores não recebem nenhum tipo de assistência técnica. Os insumos empregados no sistema de produção das hortaliças e frutas são: a) esterco de galinha, utilizado nos pólos de Tajaçuaba, Quebra Pote, Anajatiua, Santa Maria, Jardim São Cristovão II, Cumbique, Mercês, São João da Boa Vista, Coquilho, Itapera e Iguaíba; b) calcário e adubo químico (NPK), usados somente por alguns agricultores. Todos compram sementes selecionadas e, no pólo de Tajaçuaba, os agricultores produzem suas próprias sementes de berinjela, melancia, abóbora, abobrinha, maxixe e quiabo, bem como mudas de coco, mamão, maracujá e acerola.

Verificou-se que os agricultores realizam o preparo manual do solo para o plantio. Os tratos culturais consistem no transplantio, desbaste, 
envairamento, amarrio, e a irrigação ocorre com o uso de mangueira, microaspersão, gotejamento, ou "xique-xique". No caso das frutíferas, a captação de água é feita de rios, igarapés, brejos, poços "cacimbões" e poços semi-artesianos e artesianos.

Todos os produtores entrevistados empregam o controle fitossanitário pelo uso de inseticidas e fungicidas. Dentre os fungicidas utilizados destacam-se Benlate 500, Dithane PM e Cupravit Azul BR. Aproximadamente $80 \%$ dos produtores preparam a mistura dos inseticidas e fungicidas em um só veículo, sendo que a mistura é normalmente denominada de "coquetel". Pesquisas realizadas por ADISSI e SOBREIRA (1), na Paraíba, evidenciaram a prática comum do uso de "coquetéis" à base de inseticidas, fungicidas e acaricidas que, semanalmente, são alternados com outros agrotóxicos.

Poucos produtores (cerca de $5 \%$ dos entrevistados) fazem uso de formulações caseiras à base de fumo, pimenta e calda bordaleza, ou ainda de iscas preparadas com farelo de trigo, açúcar e inseticida para combater a paquinha. Em Cumbique, alguns trabalhadores rurais plantam cravo-de-defunto (Tagetes minuta Linn.) nos canteiros para o controle de nematóides.

De acordo com estudos realizados pela ASSOCIAÇÃO AGROECOLÓGICA TIJUPÁ (4) os pequenos produtores preferem o controle químico ao alternativo, devido à sua eficácia em curto prazo. Em geral, os agrotóxicos são indicados pelo vendedor, diretamente na loja de produtos agropecuários, ou pelos vizinhos, normalmente sem a utilização do receituário agronômico.

\subsection{PRINCIPAIS INSETICIDAS UTILIZADOS}

Os principais inseticidas utilizados nos pólos de produção pertencem ao grupo dos organofosforados, destacando-se: Tamaron $B R$ (Metamidofós, classe toxicológica II), Folidol 600 e Folisuper 600 BR (Paration metílico, classe toxicológica I) e Diazinon 600 CE (Diazinon, classe toxicológica II) (Tabela 3). O Tamaron BR tem sido empregado com maior freqüência, seguido pelo Folidol 600 e Folisuper 600 BR. O Diazinon 600 CE, o Agritoato 400 (Dimetoato, classe toxicológica I), o Nitrosin e o Agridion 20 (Malation, classe toxicológica IV) são utilizados em menor escala. Situação semelhante foi verificada por MOREIRA (9), na região agrícola de Viçosa (MG), sendo que 92,7 e $32,1 \%$ dos tomaticultores entrevistados utilizavam Tamaron BR e Folidol 600, respectivamente. FERRO (10), estudando a situação do uso de agrotóxicos nos municípios de Petrolina e Vitória de Santo Antão (PE), verificou que estes dois inseticidas estão entre os mais utilizados pelos trabalhadores rurais. 


\section{TABELA 3- FREQÜÊNCIA DOS PRINCIPAIS INSETICIDAS UTILIZADOS NOS PÓLOS DE PRODUÇÃO DA ILHA DE SÃO LUÍS (MA)}

\begin{tabular}{lcc}
\hline Inseticidas & $\begin{array}{c}\text { Nœmero de } \\
\text { produtores }\end{array}$ & Freq \\
\hline & 6 Crcia (\%) \\
Tamaron BR & 2 & 30 \\
Folidol 600 & 6 & 10 \\
Tamaron BR e Folidol 600 & 1 & 30 \\
Folidol 600 e Diazinon & 1 & 5 \\
Folidol 600 e Folisuper & 1 & 5 \\
Tamaron BR, Folidol 600 e Folisuper & 1 & 5 \\
Tamaron BR, Folisuper e Diazinon & 2 & 5 \\
Agritoato, Nitrosin e Agridion & & 10 \\
\hline \hline
\end{tabular}

\subsection{DOSAGEM DE INSETICIDAS}

Verificou-se que somente $45 \%$ dos produtores utilizam a dosagem recomendada nos rótulos das embalagens dos produtos, enquanto que $45 \%$ aplicam doses acima e $10 \%$ doses inferiores. A alteração da dosagem recomendada implica em conseqüências negativas ao ambiente provocando explosão de pragas secundárias pelo desequilíbrio causado com a eliminação dos inimigos naturais, bem como pelo aumento na resistência das pragas aos produtos utilizados.

\subsection{PERÍODO DE CARÊNCIA}

Do total de produtores entrevistados, $65 \%$ não observam o período de carência definido pela legislação nacional sobre o uso, produção, consumo, comércio e armazenamento de agrotóxicos, que prevê a obrigatoriedade do receituário agronômico para aquisição dos produtos. Dados apresentados por MOREIRA (9) mostraram que 99,4\% dos tomaticultores pesquisados também não obedeciam ao período de carência. 
Os resultados obtidos evidenciam que os consumidores da llha de São Luís podem estar ingerindo hortaliças contaminadas com resíduos de inseticidas organofosforados largamente empregados no controle de pragas nos pólos de produção estudados.

\subsection{UTILIZAÇÃO DE EQUIPAMENTOS DE PROTEÇÃO E DE SEGURANÇA}

Com relação às medidas de segurança, durante a preparação e a aplicação da calda inseticida, verificou-se que a maioria dos produtores entrevistados (65\%) não utiliza nenhum tipo de equipamento de proteção individual, ficando totalmente exposta aos riscos de intoxicação pelas vias dérmica e respiratória. O restante dos entrevistados utiliza algum tipo de equipamento de proteção e segurança, tais como botas de borracha, macacão, máscaras e luvas (Tabela 4). Uma das principais formas de contaminação dos trabalhadores rurais ocorre via exposição direta no momento do manuseio e aplicação do produto. A precariedade das condições de trabalho observadas nos pólos de produção decorre da falta de informações adequadas, assistência técnica e recursos financeiros para obtenção dos equipamentos de segurança e de proteção individual.

\section{TABELA 4 - FREQÜÊNCIA DE PRODUTORES QUE UTILIZAM EQUIPAMENTOS DE PROTEÇÃO INDIVIDUAL (EPI) DURANTE A APLICAÇÃO DE INSETICIDAS NOS PÓLOS DE PRODUÇÃO DE SÃO LUÍS (MA)}

\begin{tabular}{|c|c|c|}
\hline$\overline{E P I}$ & Nœmero de produtores & Freq Crncia (\%) \\
\hline Avental & 0 & 0 \\
\hline Botas de borracha & 6 & 30 \\
\hline Capa & 0 & 0 \\
\hline Macac ${ }^{a} \mathrm{O}$ & 1 & 5 \\
\hline M Ascara & 6 & 30 \\
\hline Luvas & 1 & 5 \\
\hline Nenhum & 13 & 65 \\
\hline Total * & 27 & 135 \\
\hline
\end{tabular}

* O somatório do número de produtores e a freqüência percentual de utilização de equipamentos de proteção ultrapassa 20 e 100\%, uma vez que o produtor pode fazer uso de mais de um destes equipamentos. 


\subsection{DESTINO DAS EMBALAGENS}

Verificou-se que o descarte de embalagens (Tabela 5) não obedece às normas estabelecidas pela legislação em vigor que prevê a incineração como processo mais eficiente. Além disso, o armazenamento dos agroquímicos ocorre nas próprias dependências das moradias. MOREIRA (9) também verificou a falta de preocupação dos produtores de tomate em Viçosa com o descarte das embalagens, sendo que a maior parte destas é deixada no campo. ADISSI \& SOBREIRA (1) e FERRO (10) constataram que a prática de deixar embalagens de veneno em qualquer lugar é comum em todo o país. Problemas como estes contribuem para a contaminação do ambiente pelos resíduos deixados no solo que podem poluir os recursos hídricos (lençol freático, águas superficiais e águas de abastecimento), além da flora e da fauna aquáticas.

\section{TABELA 5 - FREQÜÊNCIA PERCENTUAL DO DESTINO DADO ÀS EMBALAGENS VAZIAS PELOS PRODUTORES NOS PÓLOS DE PRODUÇÃO DA ILHA DE SÃO LUÍS (MA)}

\begin{tabular}{lcc}
\hline Destino das embalagens & $\begin{array}{c}\text { Nomero de } \\
\text { produtores }\end{array}$ & Freq Cria (\%) \\
\hline \hline Queimadas & 3 & 15 \\
Enterradas & 5 & 25 \\
Jogadas a cøi aberto & 9 & 45 \\
Reaproveitadas & 2 & 10 \\
Outras & 1 & 5 \\
\hline \hline & & \\
Total & $\mathbf{2 0}$ & $\mathbf{1 0 0}$ \\
\hline \hline
\end{tabular}

\subsection{RESULTADOS DAS ANÁLISES DE RESÍDUOS DOS PESTICIDAS}

\subsubsection{Parâmetros Cromatográficos}

Durante a análise do inseticida Metamidofós foi verificada, inicialmente, a linearidade, porém não foram injetados os padrões mais concentrados, uma vez que as concentrações presentes nas amostras encontravam-se em nível bem mais baixo (décimos de ng. $\mathrm{mL}^{-1}$ ), e a sensibilidade do detector empregado (FPD) foi extremamente alta para o 
composto em questão. Grande parte das amostras fortificadas não contribuiu para a confirmação dos resultados por conterem concentração muito elevada (acima de $1 \mathrm{mg} . \mathrm{Kg}^{-1}$ ), mascarando a área dos produtos presentes na amostra. Por isso, foram necessárias diluições dos extratos e padrões que continham maiores concentrações.

O tempo de retenção (tR) do Metamidofós, em todos os extratos, foi extremamente reprodutível com o do padrão, variando de 5,7 a 5,8 min.

No caso do Paration metílico, o sistema de detecção nitrogêniofósforo atingiu limite de detecção de $22 \mu \mathrm{g} . \mathrm{L}^{-1}$, o que justificou a escolha do mesmo para as análises futuras. Os tempos de retenção obtidos variaram de 6,8 a 6,9 min, indicando excelente reprodutibilidade.

\subsubsection{Eficiência da Metodologia Analítica}

Os resultados obtidos nos testes de recuperação do Metamidofós, em amostras fortificadas de tomate e de pimentão, revelaram percentagem média de recuperação de $98 \%$, superior à média encontrada por MOREIRA (9) que foi de 93,3\% em amostras de tomate fortificadas com Metamidofós. Para o Paration metílico, a recuperação média foi de 70\% (Tabela 6). Os resultados dos testes de recuperação mostraram que as metodologias adotadas para a extração nas matrizes vegetais foram satisfatórias para a determinação de resíduos dos princípios ativos estudados. A literatura especializada considera valores de recuperação de 70 a $120 \%$ como sendo satisfatórios em análise de resíduo (7).

\section{TABELA 6 - RESULTADOS DE RECUPERAÇÃO DO MÉTODO DE EXTRAÇÃO DOS PESTICIDAS E DE PURIFICAÇÃO DOS EXTRATOS CROMATOGRÁFICOS}

\begin{tabular}{|c|c|c|c|c|c|}
\hline \multirow[t]{2}{*}{ Pesticidas } & \multirow{2}{*}{$\begin{array}{c}\mathrm{N} \text { vel de } \\
\text { Fortifica }{ }^{\circ} \text { o }\end{array}$} & \multicolumn{3}{|c|}{ Recupera a o (\%) } & \multirow[t]{2}{*}{ MØdia* } \\
\hline & & Tomate & Piment ${ }^{\mathrm{a}} \mathrm{o}$ & Couve & \\
\hline \multirow[t]{2}{*}{ Metamidof $\mathrm{s}$} & $3 \mathrm{ppm}$ & 105,3 & - & - & \\
\hline & $0,05 \mathrm{ppm}$ & - & 90,6 & - & $98 \%$ \\
\hline $\begin{array}{l}\text { Paration } \\
\text { met lico }\end{array}$ & $0,04 \mathrm{ppm}$ & - & - & 70,0 & $70 \%$ \\
\hline
\end{tabular}

*Médias de duas repetições com duas injeções cromatográficas para cada extrato analisado. 


\subsubsection{Presença dos Pesticidas nas Amostras}

O inseticida Paration metílico não foi detectado em nenhuma das amostras vegetais analisadas (Tabela 7). A Figura 1 apresenta os cromatogramas de padrão do Paration metílico e de uma amostra de couve fortificada. Nas amostras não-fortificadas nenhum pico apareceu no tr do pesticida. Por outro lado, o inseticida Metamidofós foi encontrado em amostras de tomate, pimentão e coentro. As médias de resíduos de Metamidofós encontradas nas amostras foram de $0,046 \mathrm{mg} \cdot \mathrm{kg}^{-1}$ no tomate, $0,113 \mathrm{mg} \cdot \mathrm{kg}^{-1}$ no pimentão e $0,031 \mathrm{mg} \cdot \mathrm{kg}^{-1}$ no coentro, valores bem abaixo dos limites de tolerância permitidos $\left(0,3\right.$ e $0,4 \mathrm{mg} \cdot \mathrm{kg}^{-1}$, respectivamente, para tomate e pimentão) (11). Os cromatogramas apresentados na Figura 2 evidenciaram a presença de Metamidofós em um dos extratos de pimentão.

\section{TABELA 7 - RESULTADOS DAS ANÁLISES DE RESÍDUOS DOS PESTICIDAS}

\begin{tabular}{|c|c|c|c|c|}
\hline \multirow[b]{2}{*}{ Pesticidas } & \multicolumn{4}{|c|}{ Concentra ${ }^{a} o$ do pesticida na amostra $\left(\mathrm{mg} \cdot \mathrm{kg}^{-1}\right)$} \\
\hline & Tomate & Piment $^{\mathrm{a}} \mathrm{o}$ & Coentro & Couve \\
\hline Metamidof $\mathrm{s}^{*}$ & 0,041 & $\begin{array}{l}0,042 \\
0,087 \\
0,046 \\
0,275\end{array}$ & 0,031 & ND \\
\hline MØdia Geral & 0,041 & 0,113 & 0,031 & - \\
\hline Paration met lico & ND & ND & ND & ND \\
\hline
\end{tabular}

* Médias de 3 repetições para cada vegetal em cada localidade estudada. ND = Não-detectado.

Convém mencionar que o Metamidofós não é liberado pela legislação brasileira para controle de insetos no cultivo de coentro (1114). A presença deste pesticida nas amostras coletadas em uma das localidades estudadas evidencia falta de informação básica por parte do pequeno produtor rural que desconhece, inclusive, o tipo de produto que deve ser aplicado em determinadas culturas. Devido à sua larga utilização, o Metamidofós pode apresentar sérios riscos à saúde humana, sobretudo estando presente em quantidades acima da tolerada por estes organismos, 
seja na água, no ar, no solo ou nos alimentos (15-19). Sua toxicidade para mamíferos é relativamente elevada $(16,20-23)$ e sérios casos de intoxicação humana $(24,25)$ e em animais $(18,26)$ já foram registrados.

FIGURA 1 - CROMATOGRAMAS DE UM PADRÃO DO PARATION METÍLICO, CONCENTRAÇÃO: 5 mg. $\mathrm{L}^{-1}(\mathrm{~A})$, E DE UMA AMOSTRA DE COUVE (B), FORTIFICADA AO NÍVEL DE $40 \mu \mathrm{g} \cdot \mathrm{Kg}^{-1}$ DO INSETICIDA

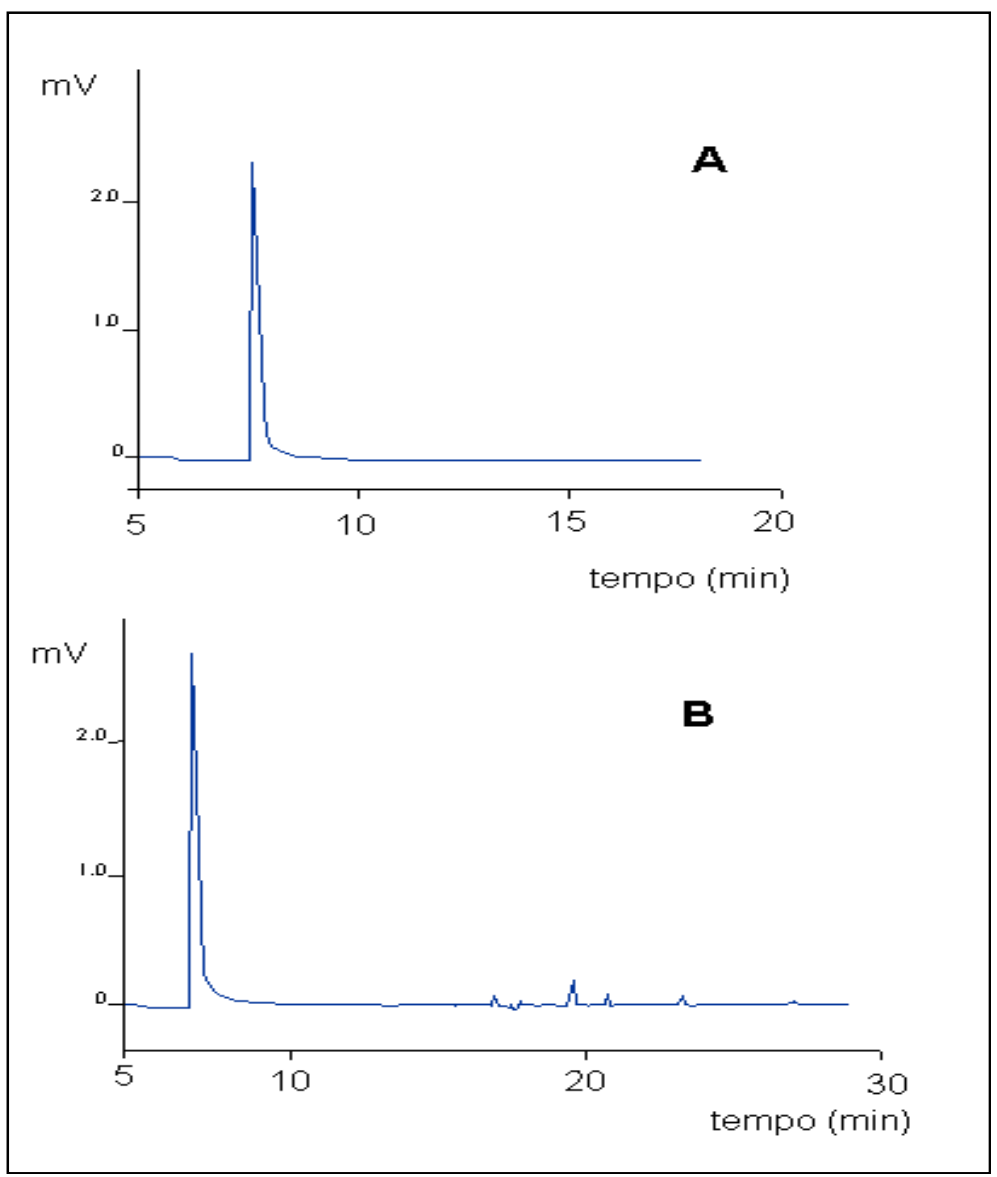


FIGURA 2 - CROMATOGRAMAS DE UM PADRÃO DO METAMIDOFÓS, CONCENTRAÇÃO: $176 \mu \mathrm{g} . \mathrm{L}^{-1}$ (A), E DE UM EXTRATO DE PIMENTÃO NÃO-FORTIFICADO (B)
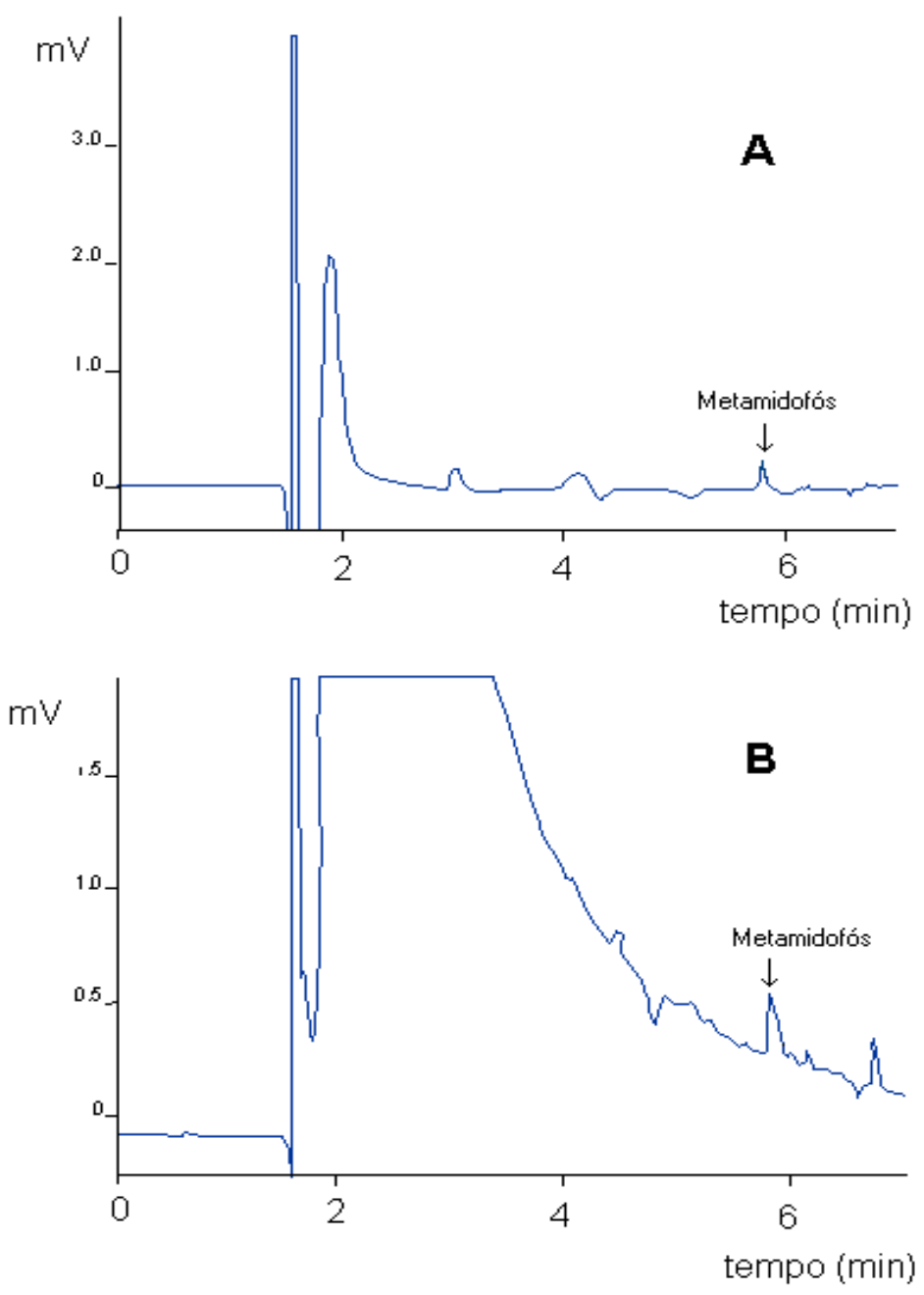
Apesar dos níveis de resíduos encontrados mostrarem-se abaixo do limite recomendado pelo Ministério da Saúde, os consumidores de hortaliças da llha de São Luís não estão livres de ingerir produtos hortícolas contendo resíduos de pesticidas. Há que se considerar que foi tomada pequena amostra, em época chuvosa do ano, e que as chuvas favorecem a lavagem dos agroquímicos nas culturas no próprio campo. Dependendo da composição química, do grau de persistência e da biodegradação, os resíduos depositados como camadas superficiais em vegetais podem ser facilmente removidos pela água de irrigação, pela chuva e pelo vento. $A$ polaridade mediana dos inseticidas estudados favorece sua remoção pela chuva $(16,17,20)$. Deve-se ressaltar, ainda, que o presente trabalho detevese na investigação de apenas dois dos princípios ativos mais utilizados no controle de insetos. A ausência de resíduos de pesticidas em alimentos, ou mesmo a presença de resíduos em níveis de subnanogramas, como é o caso, pode indicar, ainda, que estes pesticidas sofreram degradação, dando origem a compostos (metabólitos) que, em alguns casos, e dependendo de suas propriedades físico-químicas, podem ser mais tóxicos que os seus precursores $(20,22,23)$. Tais considerações, entretanto, carecem de estudos de confirmação que envolveriam técnicas cromatográficas com detecção por espectrometria de massas.

\section{CONCLUSÃO}

Embora não tenham sido detectados resíduos de pesticidas em hortaliças produzidas e comercializadas na llha de São Luís, acima dos limites de tolerância permitidos pelos órgãos governamentais competentes, verificou-se que a utilização de pesticidas nos pólos de produção é generalizada e inadequada. Os produtos são obtidos sem a utilização de receituário agronômico, não havendo nenhum tipo de assistência técnica, informação e/ou esclarecimento sobre as normas de utilização de agrotóxicos e os cuidados de segurança necessários, o que pode acarretar prejuízos à saúde dos horticultores (doenças por exposição ocupacional), intoxicação alimentar dos consumidores e contaminação das fontes de água.

O não-cumprimento dos prazos de carência pode ser considerado como uma das principais causas da contaminação dos alimentos, devido ao poder residual dos agrotóxicos. Sugere-se para resolução desses problemas mudança no sistema de produção de hortaliças empregado para sistema orgânico. Assim, o controle de pragas e doenças seria realizado de forma alternativa utilizando receitas à base de extratos de plantas e/ou produtos naturais, plantas repelentes, plantas companheiras, 
variedades resistentes, entre outras práticas essenciais para a manutenção do equilíbrio nos agroecossistemas. Além disso, são necessárias modificações urgentes na política agrícola do Maranhão visando priorizar os programas de extensão rural que contemplem, entre outras coisas, a educação ambiental que de maneira alguma contrapõe-se à produtividade.

\section{Abstract \\ USE OF ORGANOPHOSPHORUS INSECTICIDES IN THE PRODUCTION POLES OF SÃO LUÍS (MA - BRAZIL): WORK CONDITIONS AND GREENSTUFF CONTAMINATION}

The pesticide ways of utilization in production poles of São Luís, Maranhão state, Brazil were evaluated. Some cultivated greenstuff were analyzed and it was detected Methamidophos organophosphorous insecticide residues in tomatoes, chili and parsley samples. Although contamination levels were relatively low, the presence of the pesticide indicates the lack of basic information of the farmers, which apply agrochemicals indiscriminately without following the correct application periods for each culture.

KEY-WORDS: GREENSTUFF; ORGANOPHOSPHORUS INSECTICIDES.

\section{REFERÊNCIAS}

1 ADISSI, P.J.; SOBREIRA, A.E.G. Mapeamento de riscos decorrentes do uso de agrotóxicos na horticultura paraibana. João Pessoa, PB: UFPBA, 1999. 7 p. (Relatório Técnico).

2 ANDEF. Associação Nacional de Defensivos Agricolas. Disponível: <htpp://www.andef.com.br>. Acesso em: 1 de novembro de 1999.

3 FRIGHETTO, R.T.S. Impacto ambiental decorrente do uso de pesticidas agrícolas. In: MELO, I.S.M.; AZEVEDO, J.L. Microbiologia ambiental. Jaguariúna: EMBRAPA/CNPMA, 1997. p. 415-438.

4 ASSOCIAÇÃO AGROECOLÓGICA TIJUPÁ. As pragas e sua utilização pelos agricultores. São Luís, 1993. 29 p. (Mimeog.).

5 IPES. Instituto de Pesquisas Economicas e Sociais. Sinopse estatística municipal do Maranhão. São Luís (MA), 1998. v.61, 327p.

6 CODEA. Companhia Maranhense de Desenvolvimento Agroindustrial e Abastecimento. Consumo de agrotóxicos por produto. São Luís (MA), 1998. (Relatório Técnico). 
7 FDA. Food and Drug Administration. Pesticide analytical manual. Washington, 1999. v. 1.

8 NUNES, G.S.; RIBEIRO, M.L.; POLESE, L.; BARCELÓ, D. Comparison of different clean up procedures for the determination of $\mathrm{N}$-methylcarbamate insecticides in vegetable matrices by highperformance liquid chromatography with UV detection. J. Chromatography A, v. 795, p. 43-51, 1998.

9 MOREIRA, L.F. Diagnóstico dos problemas ecotoxicológicos causados pelo uso de inseticida (Metamidofós) na região agrícola de Viçosa-MG. Viçosa (MG), 1995. 95 p. Dissertação (Mestrado em Agroquímica) - Departamento de Química, Universidade Federal de Viçosa.

10 FERRO, F. A perversa história dos agrotóxicos. Disponível: $<$ http://www. bnaf.org.br/palest03.htm>. Acesso em: 25 de maio de 2000.

11 ILSI. International Life Science Intitute. Relação de substâncias para uso fitossanitário e domissanitário. São Paulo,1995. p.7885 (Portarias do Ministério da Saúde).

12 ANDREI, E. Compêndio de defensivos agrícolas: guia prático de produtos fitossanitários para uso agrícola. 6.ed. São Paulo: Andrei, 1999. $672 \mathrm{p}$.

13 AGROFIT. Uso adequado de agrotóxicos. Brasília: Ministério da Agricultura e do Abastecimento/Federação das Associações de Engenheiros Agrônomos do Brasil, 1998.

14 BRASIL. Ministério da Agricultura. Catálogo dos defensivos agrícolas. 2.ed. Brasília, 1980. 427 p.

15 BUCKINGHAM, J. Ed. Dictionary of organic compounds. 5.ed. sup.1. New York: Chapman \& Hall, 1982. 986 p.

16 CREMLYN, R.J. Agrochemicals preparation and mode of action. Guildford: John Wiley, 1990. 396 p.

17 TIBONI, E.B. Generalidades sobre inseticidas. Curitiba: Instituto de Tecnologia do Paraná, 1991. 54 p. (Boletim Técnico).

18 JUAREZ, L.M.; SANCHEZ, J. Toxicity of the organophosphorus insecticide metamidophos (O,S-dimethyl phosphoramidothioate) to larvae of the freshwater prawn Macrobrachium rosenbergii (de man) and the blue shrimp Penaeus stylirostris Stimpson. B. Environ. Contam. Toxicol., v.43, n.2, p.302-309, 1989. 
19 TOMLIN, C. (Ed.). The pesticide manual: a world compendium. $10^{\text {th }}$ ed. Cambridge: The Royal Society of Chemistry, 1994. $1340 \mathrm{p}$.

20 HASSAL, K. A. The biochemistry and uses of pesticides. $2^{\text {nd }} \mathrm{ed}$. London: Macmillan Press, 1990. 536 p.

21 HAYES, W.J. Toxicology of pesticides. Baltimore: Vaverly, 1975. $580 \mathrm{p}$.

22 SENANAYAKE, N.; KARALLIEDDE, L. Neurotoxic effects of organophosphorus insecticides. N. Engl. J. Med., v. 316, n.13, p.761-763, 1987.

23 SENANAYAKE, N.; JOHNSON, M. K. Acute polyneuropathy after poisoning by a new organophosphate insecticide. N. Engl. J. Med., v.306, n.3, p.155-157, 1982.

24 MAITRE, M.I.; SIERRA, P.; LENARDON, A.; ENRIQUE, S.; MARINO, F. Pesticide residues levels in Argentinian pasteurised milk. The Science Environment, v.155, n. 2, p.105-108, 1994.

25 GARET, D. An epidemic of pesticide poisoning in Nicaragua: implications for prevention in developing countries. Am. J. Public Health, v.83, n.11, p.1559-1562, 1993.

26 GARY, N.E.; LORENZEN, K. Effect of methamidophos on honey bees (Hymenoptera: Apidae) during alfalfa pollination. J. Econ. Entomol., v. 82, n. 4, p.1067-1072, 1989.

\section{Agradecimentos}

Os autores agradecem à Associação Agroecológica Tijupá pelo apoio durante a aplicação dos questionários nos pólos de produção da llha de São Luís (MA). 